\title{
Photosynthetic Potential and its Association with Lipid Peroxidation in Response to High Temperature at Different Leaf Ages in Maize
}

\author{
Zhenzhu Xu • Guangsheng Zhou • Guangxuan Han • \\ Yijun Li
}

Received: 4 May 2010/Accepted: 3 June 2010/Published online: 27 July 2010

(C) Springer Science+Business Media, LLC 2010

\begin{abstract}
High temperature generally constrains plant growth and photosynthesis in many regions of the world; however, little is known about how photosynthesis responds to high temperature with regard to different leaf ages. The synchronous changes in gas exchange and chlorophyll fluorescence at three leaf age levels (just fully expanded, mature, and older leaves) of maize (Zea mays L.) were determined at three temperatures $\left(30^{\circ} \mathrm{C}\right.$ as a control and 36 and $42^{\circ} \mathrm{C}$ as the higher temperatures). High temperature significantly decreased the net $\mathrm{CO}_{2}$ assimilation rate $(A)$, stomatal conductance $\left(g_{\mathrm{s}}\right)$, maximal efficiency of photosystem II (PSII) photochemistry $\left(F_{\mathrm{v}} / F_{\mathrm{m}}\right)$, efficiency of excitation energy capture by open PSII reaction centers $\left(F_{\mathrm{v}}^{\prime} / F_{\mathrm{m}}^{\prime}\right)$, photochemical quenching of variable chlorophyll fluorescence $\left(q_{\mathrm{P}}\right)$, and the electron transport rate (ETR), whereas minimal fluorescence yield $\left(F_{0}\right)$ and nonphotochemical quenching of variable chlorophyll fluorescence $\left(q_{\mathrm{N}}\right)$ were increased. The youngest fully expanded leaves had higher $A$, ETR, and $q_{\mathrm{P}}$ compared with older leaves. Higher temperature with old leaves led to significant malondialdehyde (MDA) accumulation, a proxy for lipid peroxidation damage from active oxygen species (AOS). MDA content was significantly negatively correlated with $A, F_{\mathrm{v}} / F_{\mathrm{m}}, F_{\mathrm{v}}^{\prime} / F_{\mathrm{m}}^{\prime}$, and $q_{\mathrm{P}}$.
\end{abstract}

\section{Z. Xu · G. Zhou $(\bowtie) \cdot$ G. Han · Y. Li}

State Key Laboratory of Vegetation and Environmental Change, Institute of Botany, Chinese Academy of Sciences, 20 Nanxincun, Xiangshan, Haidian, Beijing 100093, China e-mail: gszhou@ibcas.ac.cn

Z. Xu

e-mail: xuzz@ibcas.ac.cn

\section{Z. Xu · G. Zhou}

Chinese Academy of Meteorological Sciences, China Meteorological Administration, 46 Zhongguancun South Street, Haidian, Beijing 100081, China
Thus, the results suggest that photosynthetic potentials, including stomatal regulation and PSII activity, may be restricted at high temperature, together with increasing cell peroxidation, which may be closely associated with leaf age.

Keywords Photosystem II function - Leaf age · Lipid peroxidation - High temperature . Photosynthetic potential - Zea mays L.

\section{Introduction}

Environmental constraints are rather considerable in plant production in many regions of the world (Wise and others 2004). High temperature is a particular problem, with unexpected pronounced spatial and temporal variations leading to declines in plant growth and productivity (Shah and Paulsen 2003; Orbović and Poff 2007; Parent and others 2010). For instance, there is an approximate $17 \%$ relative decrease in both corn and soybean yields for each degree centigrade increase in growing season temperature (Lobell and Asner 2003). However, although extreme high temperature can result in an obvious decline in photosynthesis, a moderate increase in temperature might enhance photosynthesis and plant growth, depending on the region and the species (Taub and others 2000; Avola and others 2008; Guo and others 2010; Xu and others 2009; Parent and others 2010). Furthermore, photosystem II (PSII) is considered the most temperature-sensitive step in the photosynthetic process (Krause and Weis 1991; Qiu and Lu 2003), but there are many reports showing that PSII inhibition does not occur until leaf temperatures are quite high, usually $40^{\circ} \mathrm{C}$ and even higher (Havaux 1993; Al-Khatib and Paulsen 1999; Wise and others 2004).

Leaf age is closely correlated with photosynthetic capacity, such as the maximum electron transport rate 
(Iacono and Sommer 2000), total chlorophyll content and carotenoid composition (Yoo and others 2003), and the xanthophyll cycle (Lu and others 2001). The leaf age effects on photosynthetic capacity may reflect the nonphotochemical quenching (NPQ) and the quantum yield of PSII, which is associated with environmental stress such as drought (Haimeirong and Kubota 2003). However, for Quercus ilex plants, no differences in NPQ, xanthophyll pool content, and total antioxidant activity with respect to leaf age were observed (Omari and others 2003), and leaf age did not affect chlorophyll fluorescence in Cucurbita pepo plants (Castagna and others 2001). Thus, whether leaf age determines photosynthesis still needs to be clarified. In addition, the effects of leaf age combined with high temperature on photosynthetic and photochemical activities have not been well understood to date.

Active oxygen species (AOS) in plant tissues accumulate at higher levels under environmental stresses, including high temperature, and water deficit stress resulting in an obvious increase in lipid peroxidation and, consequently, enhanced cell membrane damage (Foyer and others 1994; Farrant and others 2004). Malondialdehyde (MDA) is a major product of lipid peroxidation induced mainly by AOS (Pryor and Stanley 1975) and therefore is useful as a marker for oxidative stress (Cakmak and Horst 1991; Munné-Bosch and Alegre 2003). An increase in AOS such as singlet oxygen $\left({ }^{1} \mathrm{O}_{2}\right)$ can lead to a decrease in the photochemical quenching coefficient $\left(q_{\mathrm{P}}\right)$, a photoinhibition index (Foyer and others 1994), indicating that AOS accumulation may be closely associated with photosynthesis. Our previous research results have indicated that the accumulation of MDA may adversely impact photosynthesis (Xu and others 2009). However, the hypothesis that peroxidation is closely associated with photosynthesis still remains to be tested.

In the present experiment, in which we used our previous similar experimental system (Xu and others 2008), we examined the effects of high temperature on the photosynthetic and photochemical activities with respect to different leaf ages, and the relationship with lipid peroxidation, to test the hypothesis that the adverse effect of high temperature on photosynthesis is linked to peroxidation in association with different leaf ages of maize.

\section{Materials and Methods}

\section{Plant Materials}

Eighty-day-old Zea mays L. plants (cv. Shendan 21) were obtained on 23 June 2004 from the field in Jinzhou, Liaoling, China, located in the maize belt of northeast China. After directly cutting from the field, within $2 \mathrm{~h}$ the whole plants were placed into an environmentally controlled growth chamber in dark conditions before being measured. We kept the base stems of all plants in water to avoid water loss, although measuring photosynthetic capacity in the laboratory, even on cut leaves, under water is feasible according to a previous report (Ainsworth and others 2003). Detaching maize plants from the field is also a useful and simple method to measure some physiological parameters, including photosynthetic capacity in a short time (Zeng and others 2002; Xu and others 2008). Growthchamber air temperatures were set to three temperature levels: $30^{\circ} \mathrm{C}$ as a control temperature and 36 and $42^{\circ} \mathrm{C}$. We set $30^{\circ} \mathrm{C}$ as the control temperature because plants were exposed to that temperature at the peak of the growing season in the local field, and it is also similar to the normal temperature condition in an experiment by Kim and others (2006). Heat stress occurs frequently in maize plants at $42^{\circ} \mathrm{C}$ (Liu and others 2008). High humidity in the growth chamber was maintained (relative humidity $=70-75 \%$ ) to avoid possible drought stress due to water evaporation caused by the high temperature (Qiu and Lu 2003). In the present experiment, leaf positions were used to investigate the effects of aging on photosynthetic activity, like the materials used in Haimeirong and Kubota (2003). Leaves from each plant were separated into three age levels for measurement: top leaves (just fully expanded), 10 days old; middle leaves, 30 days old; and bottom leaves, 60 days old.

\section{Malondialdehyde (MDA) Analysis}

The leaves were obtained within $1 \mathrm{~h}$ from those used for measurement of gas exchange and chlorophyll fluorescence, with three replicates per treatment. Fresh leaf material (about $1 \mathrm{~g}$ ) from the leaf middle section was homogenized in $2 \mathrm{ml}$ of $0.1 \%$ trichloroacetic acid (TCA) solution. The homogenate was centrifuged at $15,000 \mathrm{~g}$ for $10 \mathrm{~min}$ and $0.5 \mathrm{ml}$ of the supernatant obtained was added to $1.5 \mathrm{ml}$ of thiobarbituric acid (TBA) in $20 \%$ TCA. The mixture was incubated at $90^{\circ} \mathrm{C}$ in a shaking water bath for $20 \mathrm{~min}$, and the reaction was stopped by placing the reaction tubes in an ice-water bath. The samples were then centrifuged at $10,000 \mathrm{~g}$ for $5 \mathrm{~min}$. The absorbance of the supernatant was read at $532 \mathrm{~nm}$ (Hernández and Almansa 2002), and the value for nonspecific absorption at $600 \mathrm{~nm}$ was subtracted. The amount of MDA was calculated using an absorption coefficient of $155 \mathrm{mM}^{-1} \mathrm{~cm}^{-1}$ (Cakmak and Horst 1991).

Ion Leakage Determination

Ion leakage was determined according to García Mata and Lamattina (2001). The leaves were obtained within $1 \mathrm{~h}$ 
from those for which gas exchange and chlorophyll fluorescence were measured, with three replicates per treatment. Fresh leaves from leaf middle sections were cut into about $20-\mathrm{mm}^{2}$ pieces (1.5 g fresh mass) and placed in beakers $\left(50 \mathrm{~cm}^{-3}\right)$ with $40 \mathrm{~cm}^{-3}$ of deionized water. After incubation at $25^{\circ} \mathrm{C}$ for $12 \mathrm{~h}$ in dark conditions, the conductivity in bathing solution was determined $\left(X_{i}\right)$ with a conductivity meter (DDSJ-308A, Shanghai Science Instrument Ltd, Shanghai, China). Then the samples were heated at $85^{\circ} \mathrm{C}$ for $2 \mathrm{~h}$, and the conductivity was read again in the bathing solution $\left(X_{t}\right)$. Electrolyte leakage was expressed as a percentage of the total conductivity after heating at $85^{\circ} \mathrm{C}\left(X_{i} / X_{t}\right)$.

\section{Leaf Gas Exchange and Chlorophyll Fluorescence}

Leaf gas exchange measurements were coupled with measurements of chlorophyll fluorescence using an open gas exchange system (LI-6400F, LI-COR, Lincoln, NE, USA) with an integrated fluorescence chamber head (LI-6400-40 LCF) and data acquisition software (OPEN Software version 5.1). The gas exchange parameters were determined at $380 \mu \mathrm{mol} \mathrm{mol}^{-1}$ of $\left[\mathrm{CO}_{2}\right]$ and $1500 \mu \mathrm{mol} \mathrm{m}^{-2} \mathrm{~s}^{-1}$ of photosynthetic photon flux density (PPFD). We used the almost maximum light condition at $1500 \mu \mathrm{mol} \mathrm{m}{ }^{-2} \mathrm{~s}^{-1}$ PPFD provided with the red LED attachment to get the photosynthetic capacity parameters, although the light components were not those from the actual field (Kim and others 2004). However, this can be done to assess the difference between the different leaf ages. As gas exchange was measured, a relative constant range of vapor pressure deficit (VPD) below $2.5 \mathrm{kPa}$ was also maintained by using a desiccant column regulator to scrub the incoming airstream (Brodribb and others 2009). Three leaves were measured at three leaf age levels (top (youngest fully expanded), middle (mature), and bottom (older) leaves, respectively) for each plant, a total of three plants each time. After 30 min of dark adaptation at $25^{\circ} \mathrm{C}$, the minimal fluorescence yield $\left(F_{0}\right)$ was measured by measuring the modulated light that was sufficiently low $\left(<0.1 \mu \mathrm{mol} \mathrm{m}{ }^{-2} \mathrm{~s}^{-1}\right)$ not to induce any significant variable fluorescence, and the maximal fluorescence yield $\left(F_{\mathrm{m}}\right)$ was determined by a 0.8 -s saturating pulse at $7000 \mu \mathrm{mol} \mathrm{m}{ }^{-2}$ $\mathrm{s}^{-1}$ in the dark-adapted leaves. The leaves were then continuously illuminated for at least $15 \mathrm{~min}$ with white actinic light at an intensity of $1500 \mu \mathrm{mol} \mathrm{m}^{-2} \mathrm{~s}^{-1}$ (Lewis and others 1999; Berncchi and others 2003). The steadystate value of fluorescence $\left(F_{\mathrm{s}}\right)$ and the gas exchange parameters were thereafter recorded, and a second saturating pulse at $7000 \mu \mathrm{mol} \mathrm{m}{ }^{-2} \mathrm{~s}^{-1}$ was imposed to determine the maximal fluorescence level in light-adapted leaves $\left(F_{\mathrm{m}}^{\prime}\right)$. The actinic light was removed and the minimal fluorescence level in the light-adapted state $\left(F_{0}^{\prime}\right)$ was determined by illuminating the leaf with far-red light for $3 \mathrm{~s}$.

The fluorescence parameters were determined as follows (van Kooten and Snel 1990): maximal efficiency of PSII photochemistry, $\quad F_{\mathrm{v}} / F_{\mathrm{m}}=\left(F_{\mathrm{m}}-F_{0}\right) / F_{\mathrm{m}}$; efficiency of excitation energy capture by open PSII reaction centers, $F_{\mathrm{v}}^{\prime} / F_{\mathrm{m}}^{\prime}$; photochemical quenching of variable chlorophyll fluorescence, $q_{\mathrm{p}}=\left(F_{\mathrm{m}}^{\prime}-F_{\mathrm{S}}\right) /\left(F_{\mathrm{m}}^{\prime}-F_{\mathrm{S}}^{\prime}\right)$; nonphotochemical quenching of variable chlorophyll fluorescence, $q_{\mathrm{N}}=1-\left(F_{\mathrm{m}}^{\prime}-F_{0}^{\prime}\right) /\left(F_{\mathrm{m}}^{\prime}-F_{0}\right)$; and relative change of minimum chlorophyll fluorescence, $q_{0}=\left(F_{0}-F_{0}^{\prime}\right) / F_{0}$. The electron transport rate ETR $=\left(F_{\mathrm{m}}^{\prime}-F_{\mathrm{S}}\right) / F_{\mathrm{m}}^{\prime} \times f I \alpha_{\text {leaf }}$, where $f$ is the fraction of absorbed quanta that is used by PSII and is typically assumed to be 0.4 for $\mathrm{C}_{4}$ plants, $I$ is PPFD, and $\alpha_{\text {leaf }}$ is effective leaf absorbance, which is assumed to be 0.85 (Maxwell and Johnson 2000).

\section{Statistical Analysis}

All statistical GLM-ANOVA analyses were performed using SPSS v10.0 (SPSS, Inc., Chicago, IL, USA). After we assessed the effects of temperature and leaf age with ANOVA separately, the interaction between temperature and leaf age was analyzed using a two-way ANOVA $(p=0.05)$. Differences between the means among temperature treatments or leaf ages were compared by Duncan's multiple-range test at 0.05 probability levels. A linear regression analysis was also performed $(p=0.05)$.

\section{Results}

\section{Light Conditions Under Different Leaf Positions}

To determine the light status of different leaf levels, we measured the photosynthetically active radiation (PAR) in leaf surfaces at different leaf positions along maize plants in the middle development state on a typical clear day. PAR decreased with downward leaf positions; there was a significant difference between bottom and top/middle leaves but no obvious difference between middle and top leaves (Fig. 1a).

\section{Lipid Peroxidation and Ion Leakage}

Lipid peroxidation was evaluated by measuring MDA content in tissues subjected to high temperature. It was low at $30^{\circ} \mathrm{C}$ [90.2, 127.8 , and $144.7 \mathrm{nmol} \mathrm{g}^{-1} \mathrm{FW}$ in the youngest and fully expanded (top), mature (middle), and older (bottom) leaves, respectively], indicating increased peroxidation at low leaf positions with old age and low radiation conditions (Fig. 1b). Both high temperatures, 36 and $42^{\circ} \mathrm{C}$, led to a significant increase in both young and 

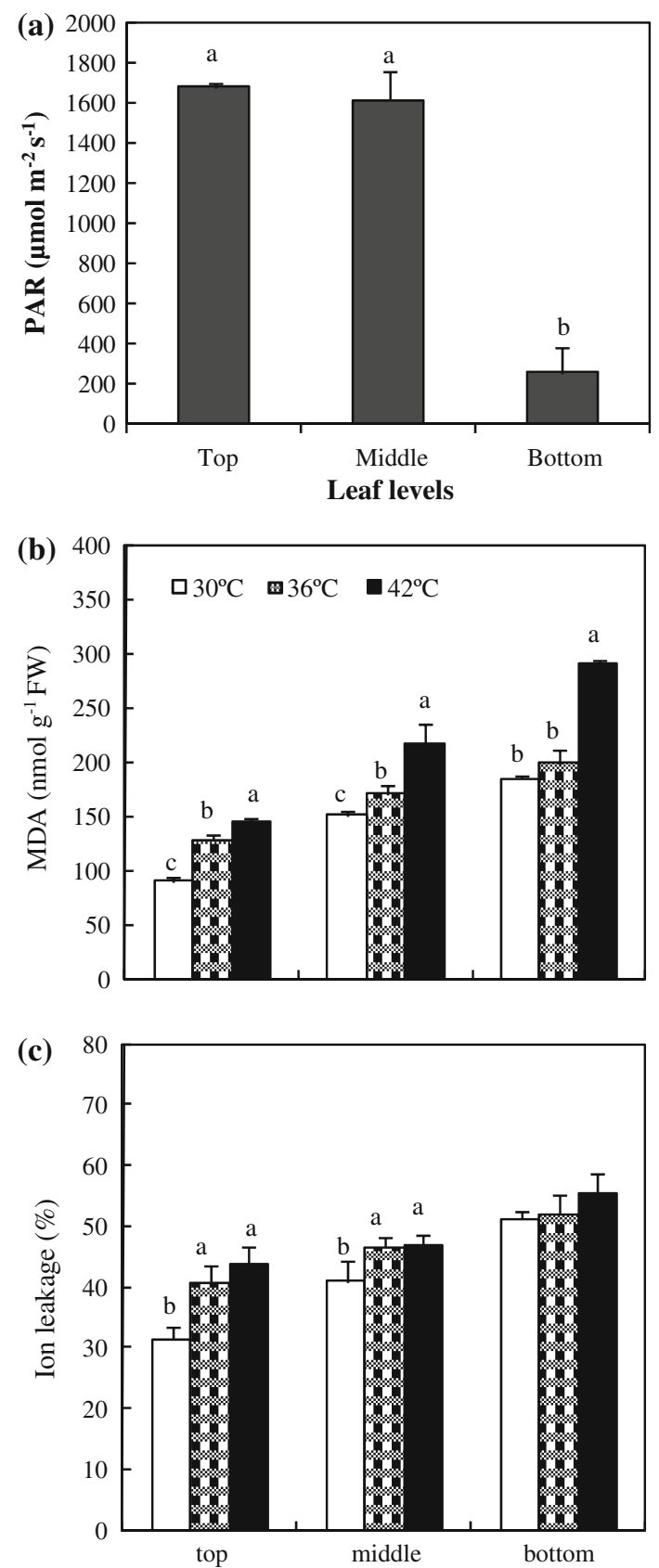

Fig. 1 Changes in PAR at different leaf levels from top to middle to bottom leaves along maize plants (a, measured at 10:00-11:00 a.m. 30 June 2004), and changes in b MDA and $\mathbf{c}$ ion leakage of young (left), mature (center), and older (right) leaves at 30,36 , and $42^{\circ} \mathrm{C}$. Mean of three replicates. Vertical bars denote standard error. For (a), different lowercase letters represent significant differences between the three leaf levels, and for (b) and (c), different lowercase letters represent significant differences within the same leaf age

mature leaves, and the highest accumulation occurred in older leaves (289.3 $\left.\mathrm{nmol} \mathrm{g}^{-1} \mathrm{FW}\right)$ at the highest temperature $\left(42^{\circ} \mathrm{C}\right)$. We also evaluated the effects across all treatments using a two-way ANOVA (Table 1). Temperature, leaf age level, and their interaction had a significant effect on MDA contents $(p<0.01$, Table 1$)$, indicating that a significant response to high temperature may occur at the three different leaf age levels.

Ion leakage is indicative of damage to cell membrane when the plant tissues were exposed to severe environmental stress. As shown in Fig. 1c, high temperature significantly increased ion leakage in both young and mature leaves, but there was no significant effect of the two high temperatures on older leaves. At all temperatures, the just fully expanded leaves experienced low ion leakage, but older leaves experienced the opposite effect. The temperature and leaf levels also significantly affected ion leakage $(p<0.01$, Table 1$)$, and their interaction was significant $(p<0.05)$, according to the two-way ANOVA.

\section{Gas Exchange}

Figure 2 demonstrates the changes in gas exchange of maize leaves subjected to high temperature at the three age levels. The high temperature of $36^{\circ} \mathrm{C}$ resulted in a slight decrease in the $\mathrm{CO}_{2}$ assimilation rate $(A)$, whereas the higher temperature of $42^{\circ} \mathrm{C}$ significantly reduced $A$ by $57.6,59.9$, and $50.7 \%$ for the youngest fully expanded, mature, and older leaves, respectively, compared to the control temperature $\left(30^{\circ} \mathrm{C}\right)(p<0.01)$ (Fig. 2a). Young leaves have a higher $A$ than older ones, irrespective of temperature. Stomatal conductance $\left(g_{\mathrm{s}}\right)$ decreased significantly under the two elevated temperatures, whereas leaf age did not affect $g_{\mathrm{s}}$ at the control temperature (Fig. 2b). The intercellular $\mathrm{CO}_{2}$ concentration $\left(C_{\mathrm{i}}\right)$ was greater at the high temperatures than at the control temperature for the youngest fully expanded and mature leaves, but high temperature did not affect $C_{\mathrm{i}}$ for older leaves with high $C_{\mathrm{i}}$ levels (Fig. 2c). High temperature led to obvious declines in the leaf transpiration rate $(E)$ in the leaves of the three age levels, whereas $E$ increased with leaf age (Fig. 2d). The temperature and leaf levels and their interaction were significant for the three gas exchange parameters $(p<0.01)$, except the interaction for $E(p>0.05)$ by the two-way ANOVA (Table 1).

\section{Chlorophyll Fluorescence}

We also determined chlorophyll fluorescence to further explore the activity of photosystem II (PSII) in maize leaves with different age levels exposed to high temperature. As shown in Fig. 3a, high temperature resulted in a significant increase in the minimal fluorescence yield $\left(F_{0}\right)$ for the three leaf ages. Conversely, maximal efficiency of PSII photochemistry $\left(F_{\mathrm{v}} / F_{\mathrm{m}}\right)$ significantly decreased at the highest temperature for the three leaf ages, and the older leaves at the highest temperature had the lowest $F_{\mathrm{v}} / F_{\mathrm{m}}$ (Fig. 3b). The efficiency of excitation energy capture by 
Table 1 Tests for temperature $(T)$, leaf level $(L)$, and their interactive effects with two-way ANOVA

\begin{tabular}{|c|c|c|c|c|c|c|c|c|c|c|c|c|}
\hline \multirow{2}{*}{$\begin{array}{l}\text { Variables } \\
\text { Source }\end{array}$} & \multicolumn{2}{|l|}{ MDA } & \multicolumn{2}{|c|}{ Ion leakage } & \multicolumn{2}{|l|}{$A_{\text {net }}$} & \multicolumn{2}{|l|}{$g_{\mathrm{s}}$} & \multicolumn{2}{|l|}{$C_{\mathrm{i}}$} & \multicolumn{2}{|l|}{$E$} \\
\hline & $F$ & $P$ & $F$ & $P$ & $F$ & $P$ & $F$ & $P$ & $F$ & $P$ & $F$ & $P$ \\
\hline $\mathrm{T}$ & 301.738 & $<0.001$ & 82.509 & $<0.001$ & 42.595 & $<0.001$ & 457.819 & 0.000 & 151.532 & $<0.001$ & 96.840 & $<0.001$ \\
\hline $\mathrm{L}$ & 547.625 & $<0.001$ & 244.574 & $<0.001$ & 114.313 & $<0.001$ & 34.654 & 0.000 & 254.831 & $<0.001$ & 19.132 & $<0.001$ \\
\hline $\mathrm{T} \times \mathrm{L}$ & 25.914 & $<0.001$ & 13.697 & $<0.001$ & 7.566 & 0.001 & 5.517 & 0.004 & 27.878 & $<0.001$ & 1.327 & 0.298 \\
\hline
\end{tabular}

For chlorophyll fluorescence parameters

\begin{tabular}{|c|c|c|c|c|c|c|c|c|c|c|c|c|}
\hline \multirow{2}{*}{$\begin{array}{l}\text { Variables } \\
\text { Source }\end{array}$} & \multicolumn{2}{|l|}{$F_{0}$} & \multicolumn{2}{|l|}{$F_{\mathrm{v}} / F_{\mathrm{m}}$} & \multicolumn{2}{|l|}{$F_{\mathrm{v}}^{\prime} / F_{\mathrm{m}}^{\prime}$} & \multicolumn{2}{|l|}{ ETR } & \multicolumn{2}{|l|}{$q_{\mathrm{p}}$} & \multicolumn{2}{|l|}{$q_{\mathrm{N}}$} \\
\hline & $F$ & $p$ & $F$ & $p$ & $F$ & $p$ & $F$ & $p$ & $F$ & $p$ & $F$ & $p$ \\
\hline $\mathrm{T}$ & 128.951 & $<0.001$ & 98.574 & $<0.001$ & 269.740 & $<0.001$ & 98.105 & $<0.001$ & 39.724 & $<0.001$ & 177.486 & $<0.001$ \\
\hline $\mathrm{L}$ & 3.518 & 0.051 & 13.338 & $<0.001$ & 23.536 & $<0.001$ & 38.058 & $<0.001$ & 26.290 & $<0.001$ & 8.591 & 0.002 \\
\hline $\mathrm{T} \times \mathrm{L}$ & 12.638 & 0.000 & 7.653 & 0.001 & 3.776 & 0.021 & 6.672 & 0.002 & 5.635 & 0.004 & 1.508 & 0.242 \\
\hline
\end{tabular}

open PSII reaction centers $\left(F_{\mathrm{v}}^{\prime} / F_{\mathrm{m}}^{\prime}\right)$ (Fig. 3c) and the electron transport rate (ETR) (Fig. 3d) had a similar trend in change to $F_{\mathrm{v}} / F_{\mathrm{m}}$. Based on the two-way ANOVA, the effects of the temperature and leaf levels, and their interaction were significant for the three parameters $(p<0.05)$, except a marginal leaf level effect for $F_{0}$ (Table 1$)$.

High temperature remarkably decreased the photochemical quenching of variable chlorophyll fluorescence $\left(q_{\mathrm{P}}\right)$ for the youngest fully expanded and mature leaves, whereas it did not affect $q_{\mathrm{P}}$ for the older leaves (Fig. 4a). Across all treatments, there were significant effects of the temperature and leaf levels, and their interaction on $q_{\mathrm{P}}$ ( $p<0.05$, Table 1). The nonphotochemical quenching of variable chlorophyll fluorescence $\left(q_{\mathrm{N}}\right)$ obviously increased at high temperatures for the three leaf ages (Fig. 4b). The effect of temperature on $q_{\mathrm{N}}$ was significant ( $p<0.05$ ), but there was no significant effect of the interaction of the two factors using the two-way ANOVA ( $p=0.242$, Table 1$)$.

Relationship Between the Parameters Related to Photosynthesis and MDA Contents

To illuminate the relationship between photosynthesis and lipid peroxidation, linear regression analyses were performed. As demonstrated in Fig. 5, there were negative and significant correlations between MDA contents and $A \quad$ (Fig. 5a, $\left.R^{2}=0.77 * *, p<0.01\right), F_{\mathrm{v}} / F_{\mathrm{m}} \quad$ (Fig. 5c, $\left.R^{2}=0.68^{* *}, p<0.01\right), F_{\mathrm{v}}^{\prime} / F_{\mathrm{m}}^{\prime}$ (Fig. $5 \mathrm{~d}, R^{2}=0.49 * *$, $p<0.05$ ), and $q_{\mathrm{P}}$ (Fig. 5e, $R^{2}=0.59^{* *}, p<0.01$ ). Both $F_{0}$ and $q_{\mathrm{N}}$ were positively correlated with MDA contents without significance $\left(R^{2}=0.30, p=0.13 ; R^{2}=0.28\right.$, $p=0.14$, respectively; Fig. $5 \mathrm{~b}, \mathrm{f})$.

Furthermore, the relationships of $A$ with $g_{\mathrm{s}}$ and $F_{\mathrm{v}} / F_{\mathrm{m}}$ were also demonstrated (Fig. 6a, b). $A$ was positively and significantly correlated with $g_{\mathrm{s}}$ and $F_{\mathrm{v}} / F_{\mathrm{m}}\left(R^{2}=0.47\right.$, $\left.p=0.04 ; R^{2}=0.52, p=0.03\right)$, indicating that stomatal conductance accounted for $47 \%$ of the change in $A$, and $52 \%$ for $F_{\mathrm{v}} / F_{\mathrm{m}}$. Thus, nonstomatal limitation may play a role in determining the carbon assimilation rate under our present experimental conditions.

\section{Discussion}

High temperature above the optimum point can limit photosynthesis, photosynthetic potentials, and PSII activity (Taub and others 2000; Crafts-Brandner and Salvucci 2002; Wollenweber and others 2003; Ristic and others 2009), depending on the species (Lewis and others 1999; Heber and others 2006; Parent and others 2010). On the other hand, senescence will be accelerated when leaves gradually become older, consequently decreasing photosynthetic function (He and others 2002; Plaut and others 2004). The loss of photosynthetic capacity at high temperature is ascribed to enhanced leaf senescence (Jiang and others 1999; Mohanty 2003). The present results indicate that photosynthetic capacity may be depressed by stomatal limitation and PSII activity under high temperature at different leaf ages, associated with enhancement of cell lipid peroxidation.

Note that the present experiment used directly excised plants from maize fields. The treatment of the materials, relative to field observation, might have some disadvantages such as cavitations that may occur in the xylem and disruption of water flow; these disadvantages might be decreased with other treatments such as putting a part of the plant under water. For ecophysiological research in the greenhouse setting, however, eliminating environmental variables from treatment variables may be simple and feasible by using leaves attached to whole plants for 

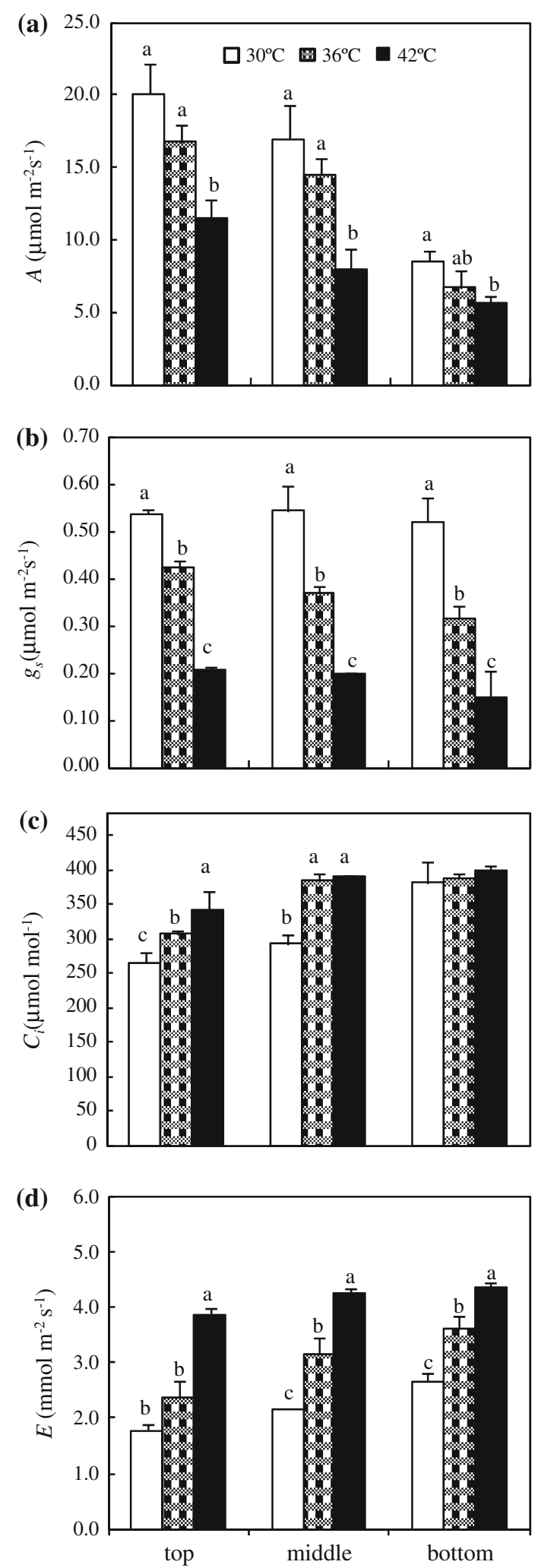

measurements of gas exchange and chlorophyll fluorescence on a short-term basis. For example, there is a body of in vitro experimental studies done in greenhouses and/or chambers that used only detached leaf discs or excised
4Fig. 2 Changes in a $\mathrm{CO}_{2}$ assimilation rate $\left(A, \mu \mathrm{mol} \mathrm{m} \mathrm{m}^{-2} \mathrm{~s}^{-1}\right)$, b stomatal conductance $\left(g_{\mathrm{s}}, \mathrm{mol} \mathrm{m} \mathrm{m}^{-2} \mathrm{~s}^{-1}\right)$, c intercellular $\mathrm{CO}_{2}$ concentration $\left(C_{\mathrm{i}}, \mu \mathrm{mol} \mathrm{mol}^{-1}\right)$, and $\mathbf{d}$ transpiration rate $(E$, mmol m $\mathrm{m}^{-2} \mathrm{~s}^{-1}$ ) of young (top), mature (middle), and older (bottom) leaves at 30,36 , and $42^{\circ} \mathrm{C}$. Mean of three replicates. Vertical bars denote standard error, and different lowercase letters represent significant differences within same leaf age

plants to help understand underlying mechanisms in response to environmental variables [for example, $\mathrm{Lu}$ and Zhang (1999) for heat stress; Xu and others (2008) for drought stress; and a review about short-term water stress by Verslues and others (2006)]. Nevertheless, for this issue, it is notable that future field investigation should be conducted.

In the current chamber experiment, there was a decline in the net $\mathrm{CO}_{2}$ acclimation rate $(A)$ from both stomatal conductance $\left(g_{\mathrm{s}}\right)$ reduction and PSII activity loss at high temperature, suggesting that the stomatal and nonstomatal limitations to carbon assimilation are comparable, being consistent with results by Kaiser (1987), Xu and Zhou (2006), and Kauffman and others (2007). In a transgenic tobacco plant, however, von Caemmerer and others (2004) reported that stomatal limitation does not contribute mainly to photosynthesis change, whereas Marques da Silva and Arrabaca (2004) indicated that stomatal limitation can play a major role in the decrease in photosynthesis in a waterstressed $C_{4}$ grass, in agreement with Schulze (1986).

In a report by Dwyer and others (2007), chlorophyll fluorescence measurements for one $\mathrm{C}_{4}$ dicot (Flaveria bidentis) showed a corresponding decrease in the quantum yield of PSII at high temperature. High temperature on cotton leaves in the field during several hot days is likely to damage photosynthesis with a limitation of photosynthetic electron transport (Wise and others 2004). However, cotton normally is grown in conditions in which photosynthesis may be limited by high temperature, whereas $g_{\mathrm{s}}$ is normally quite high (Radin and others 1994). Crafts-Brandner and Salvucci (2002) reported that the photosynthetic rate of maize declined at leaf temperatures above $38^{\circ} \mathrm{C}$, but maximal efficiency of PSII photochemistry $\left(F_{v} / F_{\mathrm{m}}\right)$ remained at a relatively constant level up to a leaf temperature of $45^{\circ} \mathrm{C}$. High temperature up to $42^{\circ} \mathrm{C}$ in the present experiment led to decreases in photosynthetic rate $(A), g_{\mathrm{s}}$, and activity of PSII at different leaf ages.

There was a negative relationship between $A$ and leaf longevity and age (Wright and Cannon 2001; He and others 2002). The older leaves of maize plants have low $A$, chlorophyll, and nitrogen contents compared to the younger leaves, indicating that old leaves senesce more profoundly (He and others 2002), as confirmed by the present experiment. Compared with older tobacco plants, chlorophyll fluorescence imaging of younger plants revealed a higher photosynthetic capacity at the plant level 

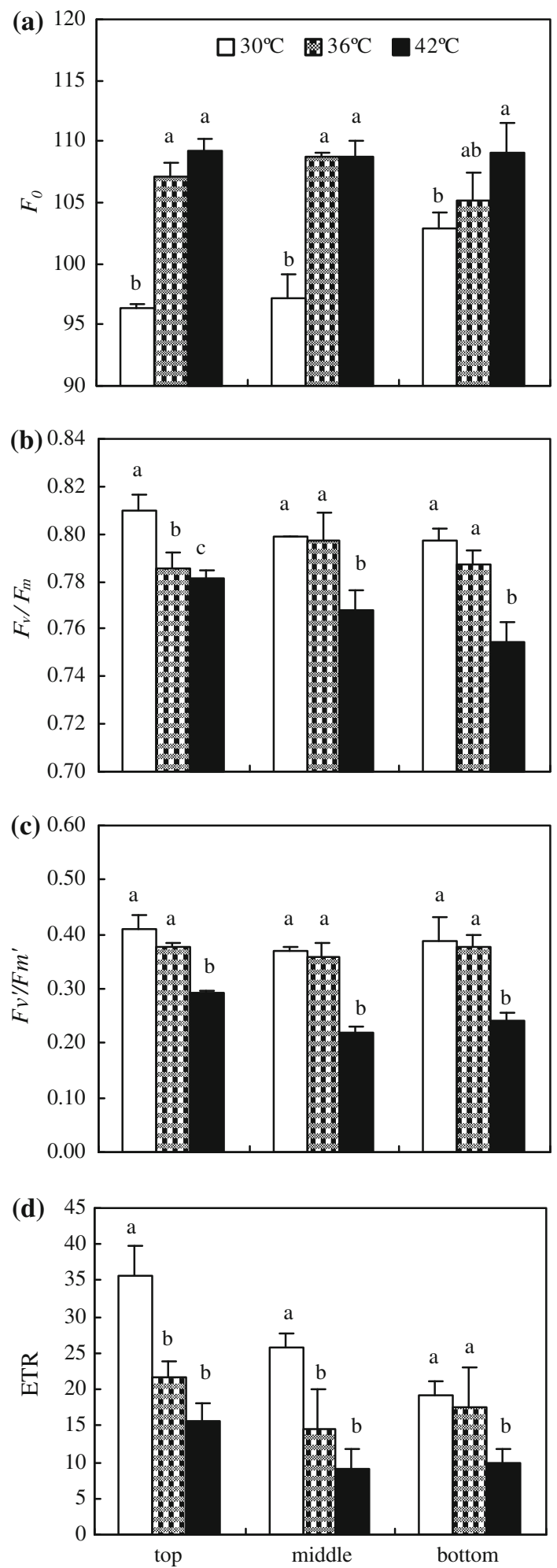

Fig. 3 Changes in a minimal fluorescence yield $\left(F_{0}\right)$, b maximal efficiency of photosystem II (PSII) photochemistry $\left(F_{\mathrm{v}} / F_{\mathrm{m}}\right)$, $\mathbf{c}$ efficiency of excitation energy capture by open PSII reaction centers $\left(F_{\mathrm{v}}^{\prime} / F_{\mathrm{m}}^{\prime}\right)$, and $\mathbf{d}$ electron transport rate (ETR) of young (top), mature (middle), and older (bottom) leaves at 30,36 , and $42^{\circ} \mathrm{C}$. Mean of three replicates. Vertical bars denote standard error, and different lowercase letters represent significant differences within same leaf age
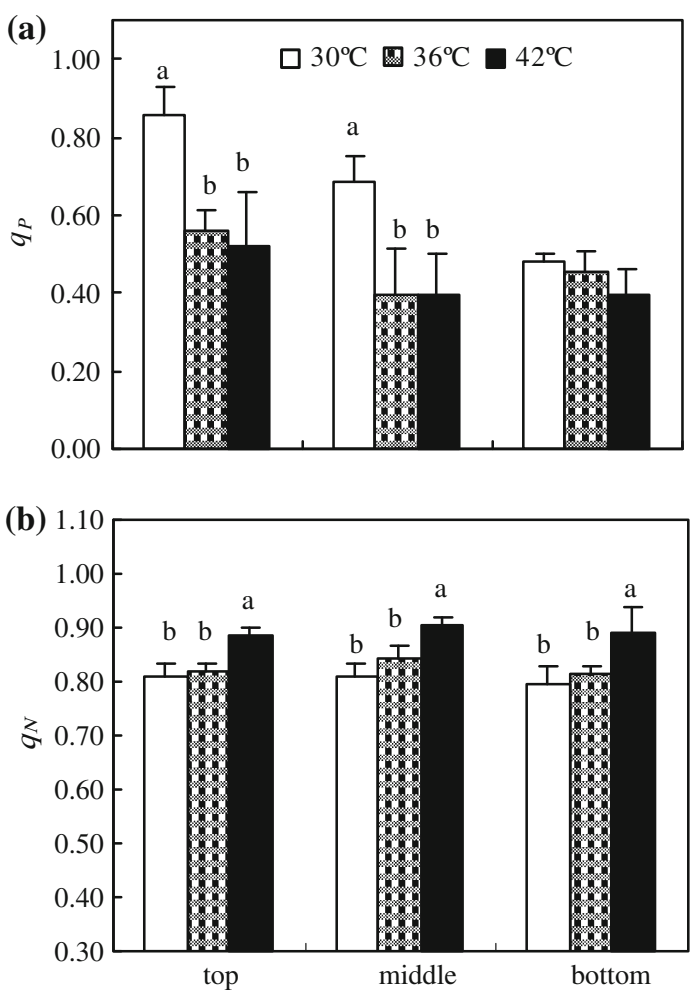

Fig. 4 Changes in a the photochemical quenching of variable chlorophyll fluorescence $\left(q_{\mathrm{P}}\right)$ and $\mathbf{b}$ the nonphotochemical quenching of variable chlorophyll fluorescence $\left(q_{\mathrm{N}}\right)$ of young (top), mature (middle), and older (bottom) leaves at 30,36 , and $42^{\circ} \mathrm{C}$. Mean of three replicates. Vertical bars denote standard error, and different lowercase letters represent significant differences within same leaf age

(Lefebvre and others 2005). The present results showed that the older leaves lost more photosynthetic capacity, including $A, F_{\mathrm{v}} / F_{\mathrm{m}}$, electron transport rate (ETR), and photochemical quenching of variable chlorophyll fluorescence $\left(q_{\mathrm{P}}\right)$, but that nonphotochemical quenching of variable chlorophyll fluorescence $\left(q_{\mathrm{N}}\right)$ was not affected by leaf age. With Trifolium repens leaf senescence, there was a decrease in $A$ that correlated with a decrease in total chlorophyll content, but the maximal efficiency of PSII $\left(F_{\mathrm{v}} / F_{\mathrm{m}}\right)$ did not decline significantly with a concomitant increase in nonphotochemical quenching (NPQ) (Yoo and others 2003), in contrast to results from our study.

Omari and others (2003) reported no differences due to plant age in NPQ, xanthophyll pool content, or total antioxidant activity. The results by Shirke (2001), however, showed that for Prosopis juliflora, photochemical efficiency of PSII during midday decreased more in both young and old leaves than in mature ones. However, for all the three leaf types there was complete recovery of photochemical efficiency at sunset from the midday depression, suggesting that midday high temperatures may lead to a loss of PSII activity but do not cause irreversible damage to the PSII apparatus. In the present study, higher 
Fig. 5 Relationships between MDA and $\mathrm{CO}_{2}$ assimilation rate $\left(A, \mu \mathrm{mol} \mathrm{m}{ }^{-2} \mathrm{~s}^{-1}\right)$,

b minimal fluorescence yield $\left(F_{0}\right)$, c maximal efficiency of photosystem II (PSII)

photochemistry $\left(F_{\mathrm{v}} / F_{\mathrm{m}}\right)$,

d efficiency of excitation energy capture by open PSII reaction centers $\left(F_{\mathrm{v}}^{\prime} / F_{\mathrm{m}}^{\prime}\right)$,

e photochemical quenching of variable chlorophyll

fluorescence $\left(q_{\mathrm{P}}\right)$, and

f nonphotochemical quenching of variable chlorophyll $\left(q_{\mathrm{N}}\right)$
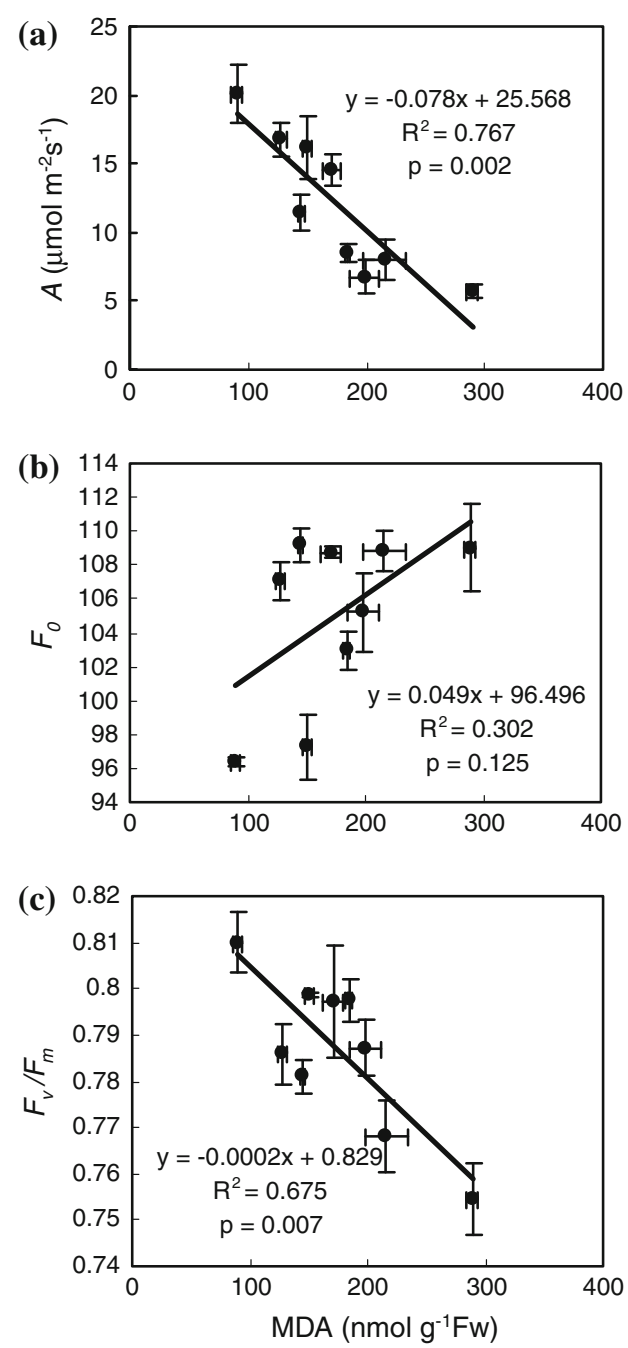

Fig. 6 Relationships between net $\mathrm{CO}_{2}$ assimilation rate $(A$, $\left.\mu \mathrm{mol} \mathrm{m} \mathrm{m}^{-2} \mathrm{~s}^{-1}\right)$ and a stomatal conductance $\left(g_{\mathrm{s}}, \mathrm{mol} \mathrm{m}^{-2} \mathrm{~s}^{-1}\right)$ and $\mathbf{b}$ maximal efficiency of PSII photochemistry $\left(F_{\mathrm{v}} / F_{\mathrm{m}}\right)$ (dimensionless)
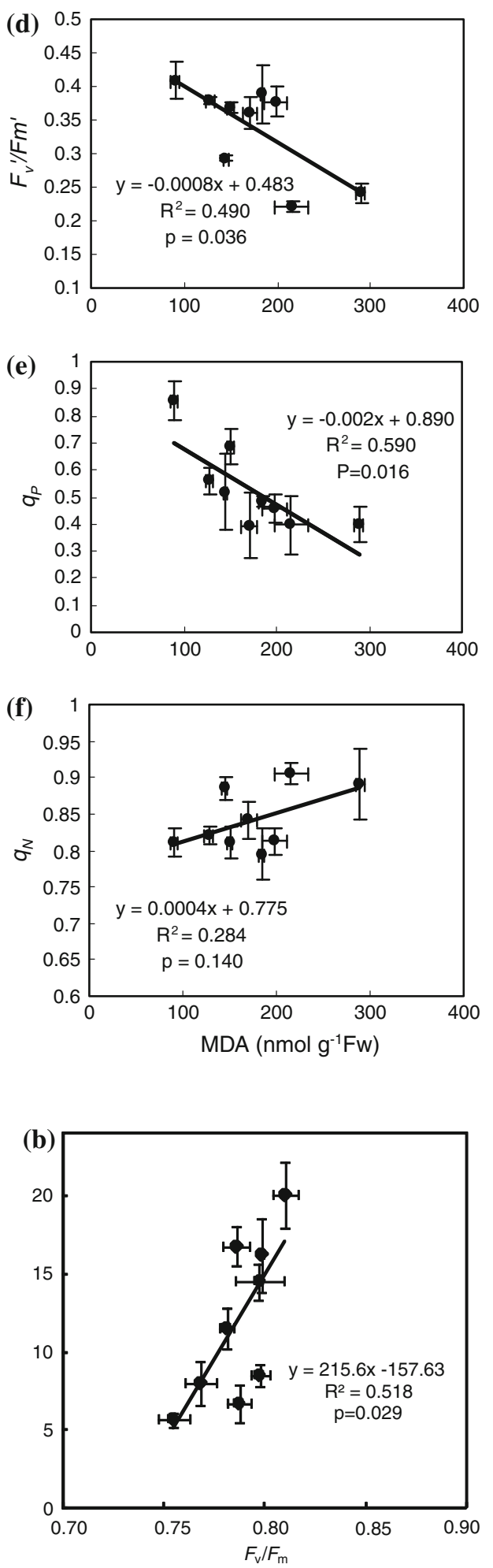

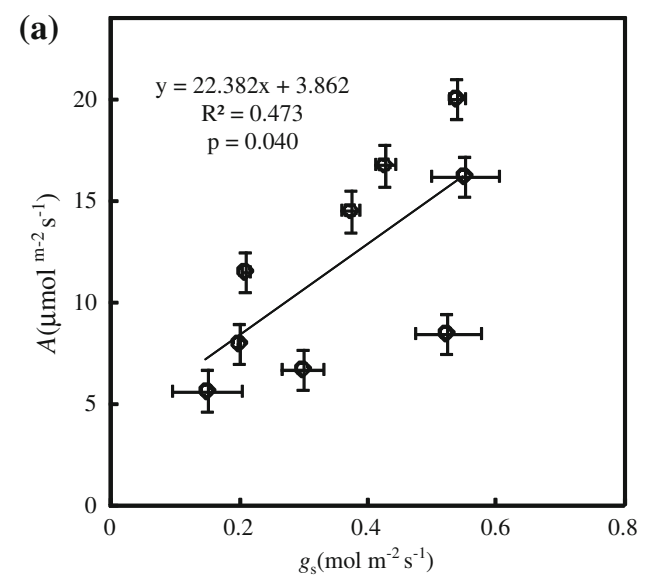

temperature resulted in a decrease in $A$ and $g_{\mathrm{s}}$ as well as in photochemical efficiency for all three leaf age levels, although the effects were different to some extent. Nevertheless, further photosynthetic study on environmental stress with leaf age is still needed.
The importance of antioxidant defenses has been identified in a number of studies and is widely reported to play a key role in environmental stress (Foyer and others 1994; Farrant and others 2004; Ogweno and others 2008). Accumulation of malondialdehyde (MDA), a marker for 
lipid peroxidation, occurs under multiple environmental stresses such as drought and heat (Munné-Bosch and Alegre 2003; Ogweno and others 2008). The present study showed that MDA accumulated to a greater extent in older leaves than in younger ones, indicating that the latter have a lower lipid peroxidation level whereas the former might tend to lose cell membrane integrity. This point is also confirmed by the enhancement of ion leakage (Fig. 1c). Moreover, the decrease in the photochemical quenching coefficient $\left(q_{\mathrm{P}}\right)$ is accompanied by an increase in the formation of singlet oxygen $\left({ }^{1} \mathrm{O}_{2}\right)$ that led to an increase in photoinhibition (Foyer and others 1994), indicating the close linkage between photosynthesis and AOS accumulation. The present study also showed that the activities of PSII are closely associated with lipid peroxidation (Fig. 5), suggesting that the effect of high temperature combined with leaf age on photosynthesis may be heavily linked to the damage to cell membranes from lipid peroxidation.

In many areas of world, high temperatures lead to a relative decrease in maize yield (Lobell and Asner 2003), although moderate temperature increases may also lead to positive responses (Guo and others 2010). It is important to understand the extent and mechanisms of $\mathrm{C}_{4}$ photosynthetic acclimation to rising temperatures (Dwyer and others 2007; Ristic and others 2009). In the present experiment, based on gas exchange and chlorophyll fluorescence parameters measured simultaneously, adverse effects of high temperature on the photosynthetic and photochemical activities were found with an enhancement of lipid peroxidation. The present finding might be of great ecophysiological significance because maize grows in many regions with continuous high temperatures during its growing season and may be subject to increased heat stress under climatic change predictions. Improvement in thermotolerance by genetic methods would enable the plant to resist early senescence due to environmental stress. Thus, a further understanding of the underlying mechanisms that allow plants to cope with high temperatures is still required.

Acknowledgments This research was funded by the National Key Basic Research Specific Foundation (2010CB951300) and the National Natural Science Foundation of China (40625015). We are greatly indebted to Liu Jingli, Shi Chunqiao, Wang Yunlong, and Yang Yang for their work during the experiment.

\section{References}

Ainsworth EA, Rogers A, Blum H, Nosberger J, Long SP (2003) Variation in acclimation of photosynthesis in Trifolium repens after eight years of exposure to free air $\mathrm{CO}_{2}$ enrichment (FACE). J Exp Bot 54(393):2769-2774

Al-Khatib K, Paulsen GM (1999) High-temperature effects on photosynthetic processes in temperate and tropical cereals. Crop Sci 39:119-125
Avola G, Cavallaro V, Patanè C, Riggi E (2008) Gas exchange and photosynthetic water efficiency in response to light, $\mathrm{CO}_{2}$ concentration and temperature in Vicia faba. J Plant Physiol 165:796-804

Berncchi CJ, Pimentel C, Long SP (2003) In vivo temperature response functions of parameters required to model RuBPlimited photosynthesis. Plant Cell Environ 26:1419-1430

Brodribb T, McAdam SA, Jordan GJ, Feild TS (2009) Evolution of stomatal responsiveness to $\mathrm{CO}_{2}$ and optimization of water-use efficiency among land plants. New Phytol 183:839-847

Cakmak I, Horst WJ (1991) Effect of aluminium on lipid peroxidation, superoxide dismutase, catalase and peroxidase activities in root tips of soybean (Glycine max). Plant Physiol 83:463-468

Castagna A, Nali C, Ciompi S, Lorenzini G, Soldatini GF, Ranieril A (2001) Ozone exposure affects photosynthesis of pumpkin (Cucurbita pepo) plants. New Phytol 152:223-229

Crafts-Brandner SJ, Salvucci ME (2002) Sensitivity of photosynthesis in a $\mathrm{C}_{4}$ plant, maize, to heat stress. Plant Physiol 129:1773-1780

Dwyer SA, Ghannoum O, Nicotra A, von Caemmerer S (2007) High temperature acclimation of $\mathrm{C}-4$ photosynthesis is linked to changes in photosynthetic biochemistry. Plant Cell Environ 30:53-66

Farrant JM, Bailly C, Leymarie J, Hamman B, Côme D, Corbineau F (2004) Wheat seedlings as a model to understand desiccation tolerance and sensitivity. Physiol Plant 120:563-574

Foyer CH, Lelandais M, Kunert KJ (1994) Photooxidative stress in plants. Physiol Plant 92:696-717

García Mata C, Lamattina L (2001) Nitric oxide induces stomatal closure and enhances the adaptive plant responses against drought stress. Plant Physiol 126:1196-1204

Guo R, Lin Z, Mo X, Yang C (2010) Responses of crop yield and water use efficiency to climate change in the North China Plain. Agric Water Manag 97(8):1185-1194

Haimeirong, Kubota F (2003) The effects of drought stress and leaf ageing on leaf photosynthesis and electron transport in photosystem 2 in sweet potato (Ipomoea batatas Lam.) cultivars. Photosynthetica 41:253-258

Havaux M (1993) Characterization of thermal damage to the photosynthetic electron transport system in potato leaves. Plant Sci 94:19-33

He P, Osaki M, Takebe M, Shinano T (2002) Changes of photosynthetic characteristics in relation to leaf senescence in two maize hybrids with different senescent appearance. Photosynthetica 40:547-552

Heber U, Bilger W, Shuvalov VA (2006) Thermal energy dissipation in reaction centres and in the antenna of photosystem II protects desiccated poikilohydric mosses against photo-oxidation. J Exp Bot 57:2993-3006

Hernández JA, Almansa MS (2002) Short-term effects of salt stress on antioxidant systems and leaf water relations of leaves. Physiol Plant 115:251-257

Iacono F, Sommer KJ (2000) Response of electron transport rate of water stress-affected grapevines: influence of leaf age. VITIS 39:137-144

Jiang CZ, Ishihara K, Satoh K, Katoh S (1999) Loss of the photosynthetic capacity and protein in senescence leaves at positions of two cultivars of rice in relation to source capacity of the leaves for carbon and nitrogen. Plan Cell Physiol 40:496-503

Kaiser WM (1987) Effects of water deficit on photosynthetic capacity. Physiol Plant 71:142-149

Kauffman GL, Kneivel DP, Watschke TL (2007) Effects of a biostimulant on the heat tolerance associated with photosynthetic capacity, membrane thermostability, and polyphenol production of perennial ryegrass. Crop Sci 47:261-267

Kim HH, Goins GD, Wheeler RM, Sager JC (2004) Stomatal conductance of lettuce grown under or exposed to different light qualities. Ann Bot 94:691-697 
Kim SH, Sicher RC, Bae H, Gitz DC, Baker JT, Timlin DJ, Eddy VR (2006) Canopy photosynthesis, evapotranspiration, leaf nitrogen, and transcription profiles of maize in response to $\mathrm{CO}_{2}$ enrichment. Glob Chang Biol 12:588-600

Krause GH, Weis E (1991) Chlorophyll fluorescence and photosynthesis: the basics. Annu Rev Plant Physiol Plant Mol Biol 42:313-349

Lefebvre S, Lawson T, Zakhleniuk OV, Lloyd JC, Raines CA (2005) Increased sedoheptulose-1,7-bisphosphatase activity in transgenic tobacco plants stimulates photosynthesis and growth from an early stage in development. Plant Physiol 138:451-460

Lewis JD, Olszyk D, Tingey DT (1999) Seasonal patterns of photosynthetic light response in Douglas-fir seedlings subjected to elevated atmospheric $\mathrm{CO}_{2}$ and temperature. Tree Physiol 19:243-252

Liu R, Li Y, Chen S, Yu Y, Hu X (2008) Effects of collaborative stress of drought and high temperature on antioxidant defense system in maize. J Henan Agric Univ 42:363-365

Lobell DB, Asner GP (2003) Climate and management contributions to recent trends in US agricultural yields. Science 299:1032

Lu C, Zhang J (1999) Effects of water stress on photosystem II photochemistry and its thermostability in wheat plants. J Exp Bot 50:1199-1206

Lu C, Lu Q, Zhang J, Kuang T (2001) Xanthophyll cycle, light energy dissipation and photosystem II down-regulation in senescent leaves of wheat plants grown in the field. Aust J Plant Physiol 28:1023-1030

Marques da Silva J, Arrabaca MC (2004) Photosynthesis in the waterstressed $\mathrm{C}_{4}$ grass Setaria sphacelata is mainly limited by stomata with both rapidly and slowly imposed water deficits. Physiol Plant 121:409-420

Maxwell K, Johnson GN (2000) Chlorophyll fluorescence: a practical guide. J Exp Bot 51:659-668

Mohanty N (2003) Photosynthetic characteristics and enzymatic antioxidant capacity of flag leaf and the grain yield in two cultivars of Triticum aestivum (L.) exposed to warmer growth conditions. J Plant Physiol 160:71-74

Munné-Bosch S, Alegre L (2003) Drought-induced changes in the redox state of alpha-tocopherol, ascorbate, and the diterpene carnosic acid in chloroplasts of Labiatae species differing in carnosic acid contents. Plant Physiol 131:1816-1825

Ogweno JO, Song XS, Shi K, Hu WH, Mao WH, Zhou YH, Yu JQ, Nogués S (2008) Brassinosteroids alleviate heat-induced inhibition of photosynthesis by increasing carboxylation efficiency and enhancing antioxidant systems in Lycopersicon esculentum. J Plant Growth Regul 27:49-57

Omari BE, Fleck I, Aranda X, Abadía A, Cano A, Arnao MB (2003) Total antioxidant activity in Quercus ilex resprouts after fire. Plant Physiol Biochem 41:41-47

Orbović V, Poff KL (2007) Effect of temperature on growth and phototropism of Arabidopsis thaliana seedlings. J Plant Growth Regul 26:222-228

Parent B, Turc O, Gibon Y, Stitt M, Tardieu F (2010) Modelling temperature-compensated physiological rates, based on the coordination of responses to temperature of developmental processes. J Exp Bot 61(8):2057-2069

Plaut Z, Butow BJ, Blumenthal CS, Wrigley CW (2004) Transport of dry matter into developing wheat kernels and its contribution to grain yield under post-anthesis water deficit and elevated temperature. Field Crops Res 86:185-198

Pryor WA, Stanley JP (1975) Letter: A suggested mechanism for the production of malonaldehyde during the autoxidation of polyunsaturated fatty acids. Nonenzymatic production of prostaglandin endoperoxides during autoxidation. J Org Chem 40: 3615-3617
Qiu N, Lu C (2003) Enhanced tolerance of photosynthesis against high temperature damage in salt-adapted halophyte Atriplex centralasiatica plants. Plant Cell Environ 26:1137-1145

Radin JW, Lu Z, Percy RG, Zeiger E (1994) Genetic variability for stomatal conductance in Pima cotton and its relation to improvements of heat adaptation. Proc Natl Acad Sci USA 91:7217-7221

Ristic Z, Momcilovic I, Bukovnik U, Prasad PV, Fu J, DeRidder BP, Elthon TE, Mladenov N (2009) Rubisco activase and wheat productivity under heat-stress conditions. J Exp Bot 60:4003-4014

Schulze ED (1986) Carbon dioxide and water vapor exchange in response to drought in the atmosphere and in the soil. Annu Rev Plant Physiol 37:247-274

Shah NH, Paulsen GM (2003) Interaction of drought and high temperature on photosynthesis and grain-filling of wheat. Plant Soil 257:219-226

Shirke PA (2001) Leaf photosynthesis, dark respiration and fluorescence as influenced by leaf age in an evergreen tree, Prosopis juliflora. Photosynthetica 39:305-311

Taub DR, Seemann JR, Coleman JS (2000) Growth in elevated $\mathrm{CO}_{2}$ protects photosynthesis against high-temperature damage. Plant Cell Environ 23:649-656

van Kooten O, Snel JFH (1990) The use chlorophyll fluorescence nomenclature in plant stress physiology. Photosynth Res $25: 147-150$

Verslues PE, Agarwal M, Katiyar-Agarwal S, Zhu J, Zhu J-K (2006) Methods and concepts in quantifying resistance to drought, salt and freezing, abiotic stresses that affect plant water status. Plant J 45:523-539

von Caemmerer S, Lawson T, Oxborough K, Baker NR, Andrews TJ, Raines CA (2004) Stomatal conductance does not correlate with photosynthetic capacity in transgenic tobacco with reduced amounts of Rubisco. J Exp Bot 55:1157-1166

Wise RR, Olson AJ, Schrader SM, Sharkey TD (2004) Electron transport is the functional limitation of photosynthesis in fieldgrown Pima cotton plants at high temperature. Plant Cell Environ 27:717-724

Wollenweber B, Porter JR, Schellberg J (2003) Lack of interaction between extreme high-temperature events at vegetative and reproductive stages in wheat. J Agron Crop Sci 189:142-150

Wright IJ, Cannon K (2001) Relationship between leaf lifespan and structural defenses in a low nutrient, sclerophyll flora. Funct Ecol 15:351-359

Xu ZZ, Zhou GS (2006) Combined effects of water stress and high temperature on photosynthesis, nitrogen metabolism and lipid peroxidation of a perennial grass Leymus chinensis. Planta 224:1080-1090

Xu ZZ, Zhou GS, Wang YL, Han GX, Li YJ (2008) Changes in chlorophyll fluorescence in maize plants with imposed rapid dehydration at different leaf ages. J Plant Growth Regul 27:83-92

Xu ZZ, Zhou GS, Shimizu H (2009) Effects of soil drought with nocturnal warming on leaf stomatal traits and mesophyll cell ultrastructure of a perennial grass. Crop Sci 49:1843-1851

Yoo SD, Greer DH, Laing WA, McManus MT (2003) Changes in photosynthetic efficiency and carotenoid composition in leaves of white clover at different developmental stages. Plant Physiol Biochem 41:887-893

Zeng XM, Lin Y, Shen YG (2002) Response of photosynthesis to light intensity in intact and detached leaves of Arabidopsis thaliana. Plant Physiol Commun 38:25-26 